\title{
Contemporary Utility of Alpha-fetoprotein Determination in Liver Disease
}

\author{
José C. Jaime-Pérez* \\ Hematology Service, School of Medicine, "Dr. José Eleuterio González" University Hospital, Autonomous University of Nuevo León, NL, Mexico
}

The alpha-fetoprotein (AFP) detected in human serum is first produced in the yolk sac and the liver during the fetal period, and is the most important protein in the first trimester of this stage of human development. Just like the very important protein albumin, the genes which code its synthesis are found in chromosome 4. There are different molecular forms of AFP, including monomers and dimers ${ }^{1}$. In pregnant women, we are able to determine fetal concentrations of this protein in the amniotic liquid, finding them elevated in cases of anencephaly and spina bifida, as well as in Down syndrome $^{2}$. When there is a suspicion of these diagnoses, the test ought to be conducted during the second trimester of pregnancy.

In the serum of adults, it is possible to detect AFP in the presence of hepatocellular carcinoma, and occasionally, in those patients who develop a teratoma and/or germ cell tumors in the pineal gland ${ }^{3}$. There are infrequent cases of a hereditary persistence of AFP, in this circumstance it is not possible to determine the cause of the abnormal elevation of the protein.

The main use of AFP determination in serum in the laboratory is to confirm the diagnosis of hepatocellular carcinoma, which is the most common primary malignancy of this organ, as well as a leading cause of death in patients with liver cirrhosis 4 . Up to $70 \%$ of patients with this malignancy present elevated AFP levels, and the concentrations within the $200-400 \mathrm{ng} / \mathrm{mL}$ range (reference range: 0.89 to $8.78 \mathrm{ng} / \mathrm{mL}$ ) in individuals in whom a hepatic tumor is detected through radiological studies confirm the diagnosis of this hepatic neoplasia with great sensitivity ${ }^{5}$.

Moreover, AFP determination has been researched as an acute liver disease indicator, mainly of a viral etiology, finding elevated values, although not in magnitude and range that they can be linked to hepatic carcinoma. This marker has also sparked interest as a subrogated indicator of non-malignant liver disease, in its chronic phase, with variable results ${ }^{6}$. Therefore, studying populations with different liver diseases become relevant and pertinent, that is, non-tumor chronic liver diseases using this serum marker.

In this issue of "Medicina Universitaria," a group of experts from a Hepatology Center presents the paper "AFP levels in patients with chronic liver diseases," where they comment on their experience with 150 patients with different liver diseases of a benign origin in addition to 10 with hepatocellular carcinoma. Benign diseases included primary biliary cholangitis, non-alcoholic steatohepatitis, autoimmune hepatitis, alcoholic hepatitis, hepatitis $B$, hepatitis $C$, and liver disease with an origin to be determined. Results confirm that AFP determination as a tumor marker is trustworthy and specific in patients with liver carcinoma, along with its ability to establish a clear difference with all other benign pathologies, since, contrary to the individuals with a malignancy, the subjects with a benign liver disease had AFP serum levels within the reference range. At the same time, the study confirms the usefulness of AFP in patients with hepatocellular carcinoma and stimulates

\section{Correspondence:}

José Carlos Jaime Pérez

E-mail: carjaime@ hotmail.com
Available online: 18-01-2019

Date of reception: 05-11-2018

Date of acceptance: 07-11-2018

DOI: 10.24875/RMU.M18000027
Medicina Universitaria. 2018;20(4):143-144 www.medicinauniversitaria.org

(he CC BY-NC-ND license (http://creativecommons.org/licenses/by-nc-nd/4.0/). 
the search for specific laboratory markers in benign chronic liver disease.

\section{References}

1. Crandall BF. Alpha-fetoprotein: a review. Crit Rev Clin Lab Sci. 1981;15:127-85

2. Park J, Cha DH, Jung JW, et al. Comparative proteomic analysis of human amniotic fluid supernatants with down syndrome using mass spectrometry. J Microbiol Biotechnol. 2010;20:959-67.
3. Caposole MZ, Aruca-Bustillo V, Mitchell M, Nam B. Benign metachronous bilateral ovarian and mediastinal teratomas with an elevated alpha-fetoprotein. Ann Thorac Surg. 2015;99:1073-5.

4. Wong RJ, Ahmed A, Gish RG. Elevated alpha-fetoprotein: differential diagnosis-hepatocellular carcinoma and other disorders. Clin Liver Dis. 2015;19:309-23

5. Arrieta O, Cacho B, Morales-Espinosa D, et al. The progressive elevation of alpha fetoprotein for the diagnosis of hepatocellular carcinoma in patients with liver cirrhosis. BMC Cancer. 2007;7:28.

6. Tai WC, Hu TH, Wang JH, et al. Clinical implications of alpha-fetoprotein in chronic hepatitis C. J Formos Med Assoc. 2009;108:210-8. 